\title{
Influence of pore ratio of clay layer on regression relationship between depth and shear wave velocity in Yuxi area
}

\author{
Tiefei $\mathrm{Li}^{1,{ }^{1},}$, XueliangC hen ${ }^{1}$, Zongchao $\mathrm{Li}^{1}$, Sen Qiao ${ }^{1}$
}

1 China, Institute of Geophysics, China Earthquake Administration

*Corresponding author.Email:2fen222@163.com

\begin{abstract}
Shear wave velocity of soil layer is a key parameter in the numerical simulation model of ground motion for various sites. For three-dimensional model, the cost of direct measurement of shear wave velocity is high. It is a common method to estimate the shear wave velocity based on the depth shear wave velocity empirical relationship. Based on the analysis of the empirical relationship between depth and shear wave velocity of various soil layers in Yuxi area, it is found that for the soil layer with obvious particle characteristics, the shear wave velocity has a significant positive correlation with particle size, and a significant negative correlation with particle roundness. The larger the water flow is, the faster the flow velocity is, the larger the sediment particles can be transported, and the smaller the particles can be transported in the water flow. The results show that the wave velocity of sediment layer is lower when the distance of transport is longer, and the wave velocity of sediment layer is higher when the distance of transport is shorter. In the field drilling data of Yuxi area, there is a significant negative correlation between void ratio and shear wave velocity, which can be further adjusted and modified by using the empirical formula of depth shear wave velocity of soil layer in Yuxi area. However, the specific gravity of soil particles has no obvious effect on its stiffness and shear wave velocity, and the specific reasons need to be further studied.
\end{abstract}

Keywords: Void ratio, Shear wave velocity, Correlation analysis

\section{玉溪地区粘土层孔隙比对其深度-剪切波速经验关系的 影响研究}

李铁飞 ${ }^{1,}{ }^{*}$, 陈学良 ${ }^{1}$, 李宗超 ${ }^{1}$, 乔森 ${ }^{1}$

1 中国地震局地球物理研究所, 北京,

* 通讯作者. 电子邮箱: 2fen222@163. com

\section{摘要}

土层剪切波速是各类场地地震动数值模拟计算模型中的关键参数。对于三维模型, 直接测量剪切波速的成本较 高, 在若干实测点位数据的基础上使用深度-剪切波速经验关系对其进行估计是一种常用的方法。本文通过分 析玉溪地区各类土层的深度-剪切波速经验关系，发现对于颗粒特征明显的土层，其剪切波速与颗粒大小有明 显的正相关关系，与颗粒的磨圆程度有明显的负相关关系，水流量越大，流速越快则其能够搬运的沉积物颗粒 
越大, 颗粒较小的沉积物在水流中搬运的距离较长, 所形成的沉积层波速较低; 较大的沉积物颗粒在水流中搬 运的距离较短, 形成的沉积层波速较高。在玉溪地区的野外钻探数据中, 孔隙比与剪切波速呈现明显的负相关 关系，可以使用孔隙比对玉溪地区土层的深度-剪切波速经验公式做进一步的调整和修正。而土粒比重对其刚 度及其剪切波速没有明显的影响，具体原因还有待进一步的研究。

关键字：孔隙比，剪切波速，相关性分析

\section{1.引言}

沉积环境是指沉积作用进行时具有的自然地理 环境, 主要包括地貌、气候、动植物、水温、水深、 水动力和水化学等因素, 构造运动也会通过影响自然 地理环境间接的影响沉积环境。沉积环境和沉积作用 的不同过程, 会在沉积产物中留下一些特征, 对土壤 而言其主要表现为土层颗粒的几何形态、结构、构造 等方面的差异 (王良忱, 1996)。其中, 水动力环境 和地貌会影响沉积物颗粒的性状, 如大小和圆度, 从 而影响其形成的沉积层的物理性质, 而构造运动会影 响沉积物的分层构造, 其他因素也会对沉积层产生一 定程度上的不同影响。沉积层不同的物理性质以及分 层结构共同构成了地下的速度结构, 从而对地震动产 生一定程度的影响。尤其对于局部地质条件, 如地表 几十米至几百米内的土壤沉积层, 这种影响十分显著。

在地震工程学中, 局部地质条件通常称为场地条 件, 国内外很多震害经都表明, 场地条件会引起地震 动局部变化以及地表震害异常, 这其中占首要地位的 因素是场地土壤的影响 (胡聿贤, 2006; 薄景山等, 2003）。在场地土壤的物理性质中, 剪切波速及其在 空间上的速度结构是对强地面运动影响最大的因素。 因此, 土层剪切波速是各类场地地震动数值模拟计算 模型中的关键参数。

土层剪切波速的获得, 需要以钻探或者地球物理 勘探为基础, 成本较高, 且对于人口、建筑密集的城 市地区, 资料的获取有很大的难度, 在若干实测点位 数据的基础上使用深度-剪切波速经验关系对其进行 估计是一种常用的方法。有研究表明, 土层颗粒的特 征会影响它们之间的孔隙大小、配位数、摩擦力等特 征, 从而影响土层的剪切波速。夏唐代等 (2011) 在 颗粒接触理论以及细观颗粒弹性力学的基础上推导 出砂土的宏观剪切波速计算公式, 认为剪切波速度受 孔隙率、应力大小及砂土颗粒弹性模量等因素影响显
著。黄博等 (2016) 引入颗粒形状修正系数, 完善了 砂土的等效剪切模量和宏观剪切波速度公式, 并指出 剪切波速随孔隙比的增大而减小。本文拟结合土的孔 隙比和土层剪切波速经验公式, 研究土层颗粒特征与 土层剪切波速的关系, 分析玉溪地区粘土层孔隙比对 其深度-剪切波速回归关系的影响。

玉溪盆地地处云贵高原西南部的盆岭分布区, 是 发育于南北向普渡河断裂带南端的一个较大的沉积 盆地, 盆地的沉积充填变化和构造演化是断裂带构造 活动的地表响应, 横贯玉溪盆地的玉溪大河与其他溪 流、泉水等在玉溪盆地内形的成树枝状水系，控制着 玉溪盆地浅表沉积层的分布与范围。玉溪盆地中的堆 积物主要为冲洪积成因。盆地边缘四周山麓中的物质 在玉溪大河等水系、带面状坡流和季节性冲洪流的作 用下，在其搬运力能够到达的区域及其下部形成冲洪 积区, 形成以河流冲击为主, 洪积、坡积为辅的沉积 土层, 水动力环境特点显著。

云南省地震灾害严重, 玉溪市经济比较发达, 人 口密度较大, 且历史上玉溪地区曾经发生 1970 年通 海 7.8 级地震, 死亡人数超过一万五千人。作为云南 省典型的山间盆地，对玉溪盆地浅表土层的剪切波速 分布的深入研究, 对于地震场地效应、盆地效应的研 究有重要意义。因此, 本文选取玉溪盆地作为代表, 研究水动力环境与沉积土层剪切波速的关系。

\section{2.玉溪地区土层的颗粒特征与剪切波速的关 系}

李铁飞（2016）使用中国地震科学台阵探测项目 在玉溪盆地进行的 16 个钻孔的钻探及剪切波测井工 作所得到的资料, 对钻孔柱状图及波速测试结果进行 整理, 得到了各土层的层平均波速、深度、厚度、以 及钻孔柱状图对该土层的描述中的颗粒大小、颗粒圆 度等土层颗粒特征, 并分析了玉溪盆地具有明显颗粒 特征的土层的剪切波速与埋深的相关性, 认为玉溪盆 
地浅层土层的剪切波速与其颗粒特征有一定的关系, 在洪积、坡积沉积环境中形成的土层如角砾层、砾石 层，其颗粒较大而磨圆度低，剪切波速较高; 在河流 沉积环境中形成的土层如细砂层、圆砾层, 其颗粒较 小而磨圆度高，剪切波速较低。

为了研究玉溪地区剪切波速与颗粒特征的关系, 尝试把数据按照磨圆程度和颗粒大小进行沉积物的
重新分类: 并重新进行拟合与分析。按照磨圆程度分 类后，其拟合结果见表 1 及图 1 。由结果可知，在玉 溪地区，对于磨圆度特征明显的土层，其剪切波速与 颗粒的磨圆程度呈现负相关，磨圆程度越差，则其剪 切波速越高。按照颗粒大小分类后，其拟合结果见表 2 及图 2。由结果可知, 在玉溪地区, 沉积物颗粒大 小与剪切波速呈现正相关，沉积物颗粒越大，则其剪 切波速越高。

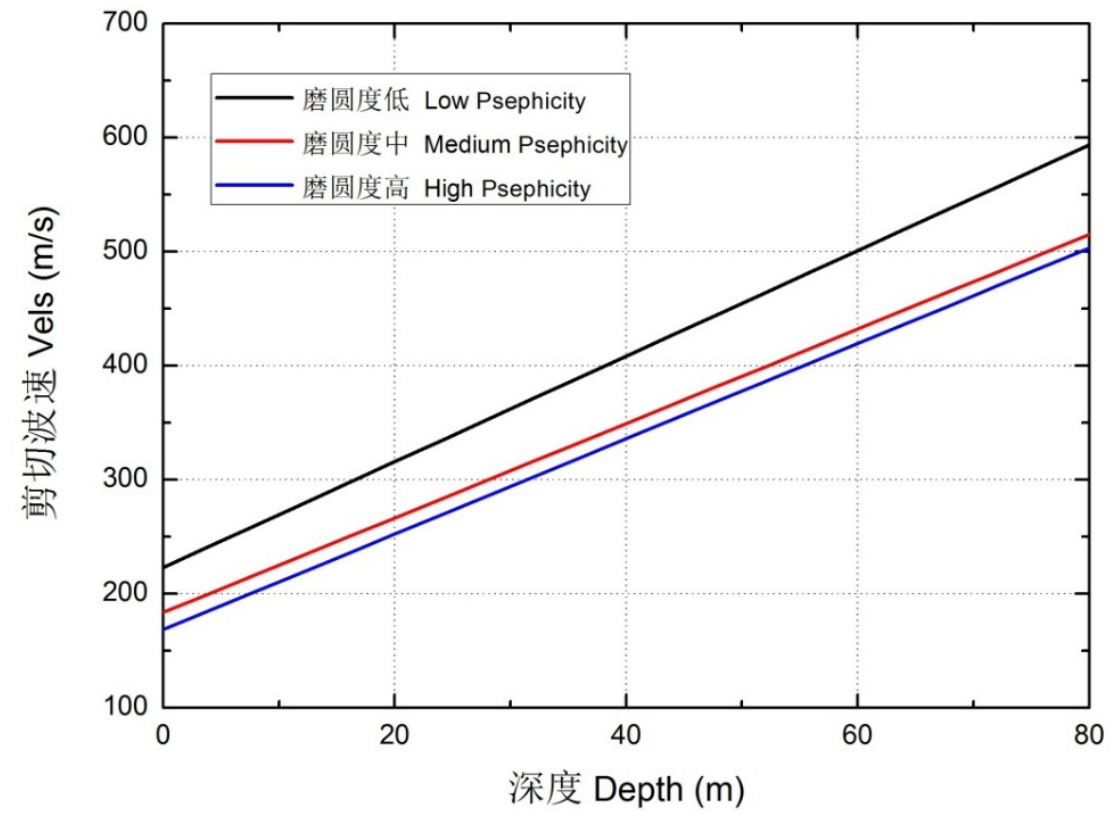

图 1 磨圆程度不同的土层的深度-波速线性拟合结果

表 1 磨圆程度不同的土层的深度-波速线性拟合结果

\begin{tabular}{|c|c|c|c|c|c|}
\hline \multirow{2}{*}{ 沉积层类别 } & \multirow{2}{*}{ 拟合函数 } & \multicolumn{2}{|c|}{ 回归参数值 } & \multirow{2}{*}{ 矫正 $\mathrm{R}$ 方差 } & \multirow{2}{*}{ 平均方差 } \\
\hline & & $\mathrm{a}$ & $\mathrm{b}$ & & \\
\hline 磨圆程度低 & \multirow{3}{*}{$\mathrm{Y}=\mathrm{a}+\mathrm{bX}$} & 223.1 & 4.632 & 0.85612 & 1697 \\
\hline 磨圆程度中 & & 183.6 & 4.143 & 0.86299 & 1669 \\
\hline 磨圆程度高 & & 168.7 & 4.181 & 0.89881 & 1444 \\
\hline
\end{tabular}

表 2 颗粒大小不同的土层的深度-波速线性拟合结果

\begin{tabular}{|c|c|c|c|c|c|}
\hline \multirow{2}{*}{ 沉积层类别 } & \multirow{2}{*}{ 拟合函数 } & \multicolumn{2}{|c|}{ 回归参数值 } & \multirow{2}{*}{ 矫正 $\mathrm{R}$ 方差 } & \multirow{2}{*}{ 平均方差 } \\
\hline & & $\mathrm{a}$ & $\mathrm{b}$ & & \\
\hline 颗粒小 & \multirow{3}{*}{$\mathrm{Y}=\mathrm{a}+\mathrm{bX}$} & 184.1 & 4.103 & 0.81442 & 2137 \\
\hline 颗粒中 & & 204.6 & 3.811 & 0.81925 & 1985 \\
\hline 颗粒大 & & 216.1 & 4.624 & 0.86648 & 2121 \\
\hline
\end{tabular}




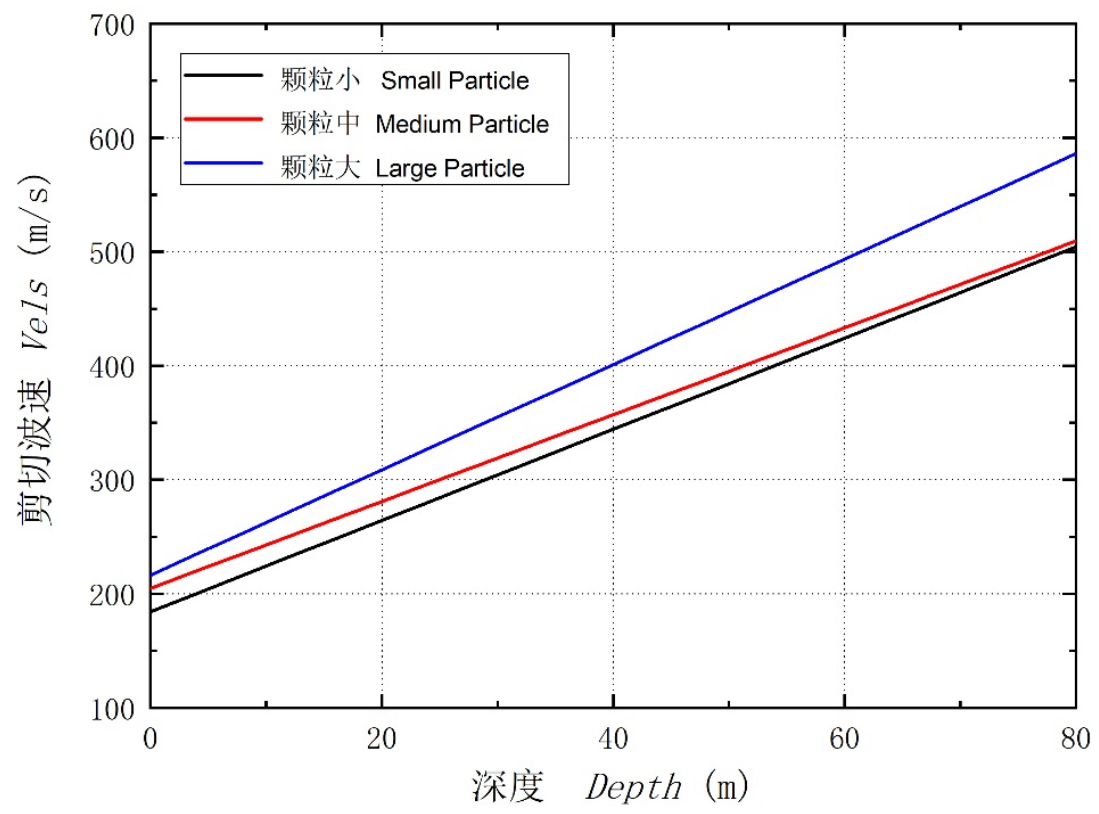

图 2 颗粒大小不同的土层的深度-波速线性拟合结果

水流的搬运能力会显著的影响沉积物颗粒大小, 水流量越大，流速越快，则沉积物颗粒越大，同时， 在搬运过程中颗粒被水流侵蚀、互相碰撞，其磨圆程 度会增高。因此，在玉溪盆地区域内，其浅层土层沉 积环境会对剪切波速产生显著的影响, 具体表现为颗 粒特征与剪切波速的不同关系。颗粒较小，磨圆度较 高的颗粒所形成的沉积层波速较低; 颗粒较大, 磨圆 度较差的颗粒形成的沉积层波速较高。

这可能是由于不同颗粒大小与磨圆度对沉积土 层的密实程度、孔隙比特征的影响, 另一方面是由于 沉积物颗粒由于沉积物源不同, 其本身的弹性模量有 一定的差异。因此, 本文将引入沉积颗粒的理论剪切 波速公式, 分别针对沉积土层的孔隙比和沉积颗粒的 比重两个方面, 分析其与沉积层剪切波速的关系, 从 而初步判断沉积环境特征对土层剪切波速的影响程 度, 以及沉积物源对土层剪切波速的影响程度。

\section{3.理论剪切波速公式}

颗粒接触理论将土层的微观结构, 如颗粒形状、 孔隙比, 和土层宏观的剪切波速联系起来, 并给出了 明确的剪切波速公式, 为本文土层颗粒特征和土层剪 切波速的经验关系研究提供了基础。H Brandt(1955) 以 Hertz 的颗粒结触理论为应力一应变分析的基础, 将介质中的固相材料看成是许多颗粒的堆积体, 将颗
粒的形状看作理想化的球粒，提出了最早的土中波的 颗粒模型分析法。J Duffy 和 R D Mindlin (1957)以 Hertz 球粒接触理论为依据, 推导了堆积体的表观微 分形式的应力-应变方程，研究了能量损耗的规律。

假设砂土等效剪切模量为干燥状态下砂土介质 中固相砂土颗粒骨架的等效剪切模量。Walton(1987) 得出了在干燥状态下球形颗粒的致密堆积体的等效 剪切模量:

$$
\mathrm{G}_{\mathrm{s}}=\frac{\mathrm{c}(1-\varnothing)}{20 \pi \mathrm{R}}\left(\mathrm{S}_{\mathrm{n}}+1.5 \mathrm{~S}_{\mathrm{r}}\right)
$$

式中, $R$ 为球状颗粒半径, $\varnothing$ 为孔隙度, $S_{n}$ 为法 向接触刚度, $\mathrm{S}_{\mathrm{r}}$ 为切向接触刚度, $\mathrm{c}$ 为配位数, 即平 均每个颗粒与其他颗粒接触的点数。

钟晓雄（1992）给出的等效剪切模量表达式为:

$$
\mathrm{G}_{\mathrm{s}}=\frac{\mathrm{c}\left(2+3 \frac{\mathrm{S}_{\mathrm{n}}}{\mathrm{S}_{\mathrm{r}}}\right)}{20 \pi \mathrm{R}(1+\mathrm{e})} \mathrm{S}_{\mathrm{n}}
$$

式中, $\mathrm{e}$ 为孔隙比。

周志军等 (2008) 引入颗粒形状修正系数来描述 任意形状颗粒与等效后的球形颗粒半径之间的差异, 得到散粒体等效剪切模量表达式为

$$
\mathrm{G}_{\mathrm{s}}=\frac{3 \mathrm{c \eta}}{8 \pi \mathrm{R}(1+\mathrm{e})^{2}}\left(\frac{4}{15} \mathrm{~S}_{\mathrm{n}}+\frac{6}{15} \mathrm{~S}_{\mathrm{r}}\right)
$$


式中, $\eta$ 为形状修正系数。

根据目前主流的理论等效剪切模量公式，可以明 确认为土层的剪切波速与孔隙比呈现负相关关系，而 同时土层剪切波速与土粒本身的刚度成正相关关系。 本文拟采用实测的剪切波速和土工试验结果对玉溪 盆地的土层数据中的比重和颗粒孔隙度进行分析, 从 而验证玉溪地区土粒的比重与其刚度、剪切波速是否 有明显的联系。

\section{4.孔隙度与深度-剪切波速经验关系研究}

本文首先分析了玉溪地区各类土层的深度-剪切 波速经验关系, 给出了玉溪盆地浅层 $80 \mathrm{~m}$ 范围内, 角 砾层、砾石层、砾砂层、细砂层和淤泥质黏土层的剪 切波速经验关系，从而进一步分析孔隙比、土粒比重 与剪切波速的关系。
在分析之前, 首先对土层按照深度-剪切波速公 式进行归一化处理, 得到实际剪切波速与土层深度的 经验剪切波速的差值; 随后将该差值与土层的孔隙度、 土粒比重分别进行分析，分析结果见表 3, 表 4, 图 3 。

由结果可见，土粒比重与剪切波速的拟合结果， 其斜率不显著异于 0 , 可以认为土粒比重对其刚度及 其剪切波速没有明显的影响。这一结论与传统的认知 不符, 暂时只能局限于野外数据的统计应用中。

同时, 孔隙比与剪切波速呈现明显的负相关关系， 与理论分析相符, 这表明, 可以使用孔隙比对玉溪地 区土层的深度-剪切波速经验公式做进一步的调整和 修正。

表 3 玉溪盆地部分钻孔土粒比重与剪切波速的相关性分析

\begin{tabular}{|c|c|c|c|c|c|}
\hline & 截距 & 截距 & 斜率 & 斜率 & 调整后 $\mathrm{R}$ 平方 \\
\hline 土粒比重 & 2.73747 & 0.00318 & $9.71 \mathrm{E}-05$ & $8.57 \mathrm{E}-05$ & 0.01033 \\
\hline 波速误差 & -11.5516 & 5.57805 & 0.62866 & 0.15037 & 0.379 \\
\hline
\end{tabular}

表 4 玉溪盆地部分钻孔土层孔隙比与剪切波速的相关性分析

\begin{tabular}{|c|c|c|c|c|c|}
\hline & 截距 & 截距 & 斜率 & 斜率 & 调整后 $\mathrm{R}$ 平方 \\
\hline 孔隙比 & 0.92937 & 0.02493 & -0.00193 & $6.72 \mathrm{E}-04$ & 0.21238 \\
\hline 波速误差 & -12.6244 & 5.09008 & 0.63358 & 0.13722 & 0.42942 \\
\hline
\end{tabular}
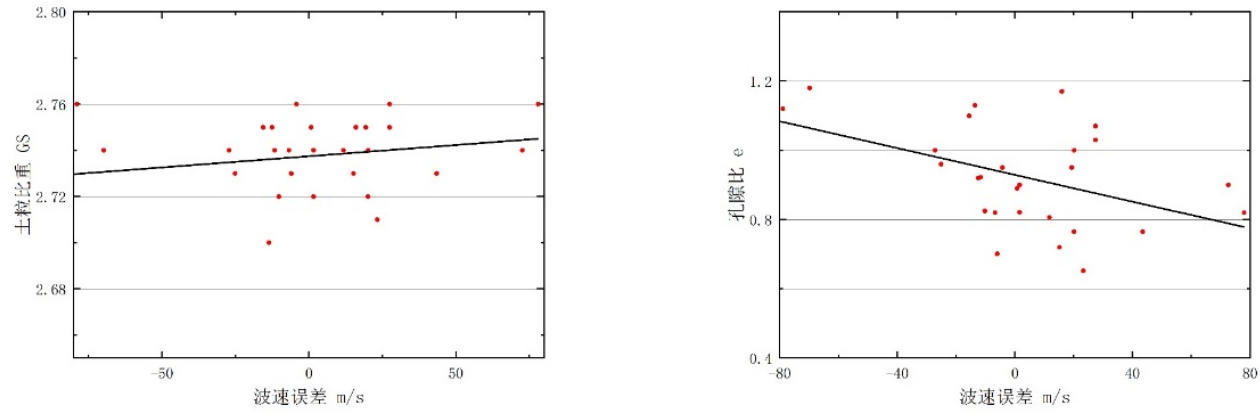

图 3 玉溪盆地部分钻孔土粒比重(左)、孔隙比（右）与剪切波速的相关性分析 


\section{5.结论与讨论}

本文讨论了玉溪盆地土层颗粒特征与土 层剪切波速的经验关系, 认为在玉溪盆地区域 内, 其浅层土层沉积环境会对剪切波速产生显 著的影响, 具体表现为颗粒特征与剪切波速的 不同关系。颗粒较小, 磨圆度较高的颗粒所形 成的沉积层波速较低; 颗粒较大, 磨圆度较差 的颗粒形成的沉积层波速较高。

随后，本文根据理论剪切波速公式，分析 了土层孔隙比、土粒比重与剪切波速的关系, 发现在玉溪地区的野外钻探数据中, 孔隙比与 剪切波速呈现明显的负相关关系, 可以使用孔 隙比对玉溪地区土层的深度-剪切波速经验公 式做进一步的调整和修正。而土粒比重对其刚 度及其剪切波速没有明显的影响, 具体原因还 有待进一步的研究。

\section{致谢}

本项目受到中国地震局地球物理研究所 中央级公益性科研院所基本科研业务专项 “土 层沉积特征与剪切波速的空间分布研究” (编 号 DQJB19B28）的资助。

\section{参考文献}

[1] 王良忱. 1996. 沉积环境和沉积相 [M]. 石油工业出版社.

[2] 胡聿贤. 2006. 地震工程学 $[M]$. 第二 版. 北京: 地震出版社.

[3] 薄景山, 李秀领, 李山有. 2003. 场地 条件对地震动影响研究的若干进展 $[\mathrm{J}]$. 世界地震工程，19(2)：11-15.

[4] 夏唐代, 刘瑜, 吴明, 周新民. 基于颗 粒接触理论的深层砂土剪切波速度 $[\mathrm{J}]$. 哈尔滨工业大学学报, 2011，43(4) : 99103.

[5] 黄博, 夏唐代, 周新民, 刘志军. 基于 微观尺度的砂土剪切波速度 $[\mathrm{J}]$. 中南大 学学报 (自然科学版), 2016,

47 (6) :2001-2006.
[6] 李铁飞, 陈学良, 李宗超. 玉溪盆地浅 层土层颗粒特征与剪切波速的关系研究 [J]. 地震学报, 2016，38(6)：934941.

[7] H Brandt, L Habra and Calif. A study of the speed of sound in porous granular media[J]. Journal of applied mechanies, 1955, 22:479486.

[8] J Duffy, RD Mindlin. Stress - strain relations and vibrations of a granular medium. J. appl. mech, 1957, $24: 585-593$.

［9］钟晓雄, 袁建新. 散粒体的微观组构与 本构关系 $[\mathrm{J}]$. 岩土工程学报, 1992 (s1) : 41-50.

[10］周志军，朱宏祥，张熠. 土石混合料结 构强度的微观分析 $[\mathrm{J}]$. 中国公路学报, 2008，21(3):30-34. 